\title{
The Safety and Effectiveness of a Novel Annular Keratopigmentation Method: A Case Report
}

\author{
Francis Ferrari $^{\mathrm{a}} \quad$ Robbert van Haselen ${ }^{\mathrm{b}}$ \\ ${ }^{a}$ Centre d'Ophtalmologie FUTURA, Strasbourg, France; 'b International Institute for \\ Integrated Medicine, Kingston, UK
}

\section{Keywords}

Femtosecond-assisted annular keratopigmentation - Procedural safety · Aesthetic results .

Patient satisfaction

\begin{abstract}
Background: We investigated the safety and effectiveness of a novel aesthetic femtosecondassisted annular keratopigmentation technique. Case Report: A 21-year-old female patient in good general and ophthalmological health with the wish to change the colour of her eyes was treated with a femtosecond-assisted annular keratopigmentation technique. Pigment was inserted in a channel in the cornea (external diameter $9.3 \mathrm{~mm}$; internal diameter $5.5 \mathrm{~mm}$ ) created with a femtosecond laser at a depth of $225 \mu \mathrm{m}$. Eight months post-operatively, there were no signs of leakage, diffusion, inflammation or any other detrimental effects on the cornea both objectively and subjectively. Conclusion: This procedure is a promising safe and effective option for those who want annular keratopigmentation for aesthetic reasons.
\end{abstract}




\section{Case Reports in Ophthalmology}

\section{Introduction}

Corneal tattooing has been in long use and was first mentioned by Galen in the 1st century [1]. These techniques are mainly used for therapeutic purposes, in patients with iris defects [2-4], corneal scars [5, 6], leukocoria [7], strabismic diplopia [8], and Urrets-Zavalia syndrome [9]. Further improvements in the surgical techniques as well as the dyes used have led to an increasing interest in corneal tattooing for aesthetic purposes in recent years. Little is known, however, about the safety and effectiveness in healthy human subjects. We report on the safety and effectiveness of a novel aesthetic keratopigmentation method in a clinical case.

This case is reported in accordance with the CARE Clinical Case Reporting guideline [10]. The subject provided written informed consent for publication.

\section{Case Report}

Subject Information and Presenting Concerns

A 21-year-old female of Maghreb origin with the wish to change the colour of her eyes presented herself at the clinic. The subject met the eligibility criteria for the procedure: she was in good general health and had no corneal damage; corneal cell-count was not $<2,500$ cells per square millimetre; she had no cataract, no keratoconus, and no retinal abnormalities. Written consent was obtained after the nature and potential risks of the procedure were explained.

\section{Clinical Findings and Diagnostic Assessment}

The following parameters were assessed: corneal endothelial cell count (specular microscope, SP-1P, Topcon Corporation, Tokyo, Japan); visual field (Model 745, Zeiss Humphrey Instruments, Jena, Germany); refraction in dioptres and visual acuity in logMAR; pachymetry and topography (Topographer, TMS-5, Tomey Corporation, Aichi-ken, Japan); and intra-ocular pressure (Kerato Refractometer KR-1, Topcon Corporation).

The pre-operative (May 18, 2016) and post-operative values for corneal endothelial cell count, refraction and visual acuity, pachymetry and intra-ocular pressure are given in Table 1. The differential topographical maps are provided as online supplementary material (for all online suppl. material, see www.karger.com/doi/10.1159/000485554).

Time Line

Key aspects of the case report are chronologically summarized in Figure 1.

\section{Surgical Procedure and Outcome Assessment}

The pre-operative procedure was as follows: Blephaclean wipes for cleaning the eyelids (1 per eye), twice daily, from 3 days before until the morning of the operation. Five minutes before surgery, a drop of oxybuprocaine $0.4 \%$ was instilled in both eyes.

The surgical procedure was as follows: the patient was placed under the laser (femtosecond laser VisuMax ${ }^{\circledR}$, Carl Zeiss Instruments, Jena, Germany), and the centre of the cornea was marked with methylene blue. After positioning of the laser cone, the eyes were treated 
Ferrari and van Haselen: The Safety and Effectiveness of a Novel Annular Keratopigmentation Method: A Case Report

with the Intra-Corneal Ring (ICR) ${ }^{\circledR}$ program, making a tunnel for insertion of intracorneal rings (used in the treatment of keratoconus or moderate myopia). The surgical parameters were as follows: external diameter, $9.3 \mathrm{~mm}$; internal diameter, $5.5 \mathrm{~mm}$; depth incision, 225 $\mu \mathrm{m} ; 2$ radial incisions at $90^{\circ}$ and $270^{\circ}$. The tunnel was then dissected with a specially developed and patented [11] round spatula (reference P5042A and P5043A, Duckworth and Kent, Baldock, UK), which was followed by the insertion of the pigment Neoris ${ }^{\circledR}$-Biotic (Paris, France) using the same spatula.

The post-operative regimen was as follows: azithromycin (Azyter) eyewash 1 drop twice daily, starting $2 \mathrm{~h}$ after the operation, for 3 days; dexamethasone (Dexafree) eyewash 1 drop twice daily, starting $2 \mathrm{~h}$ after the operation, for 2 weeks; trehalose (Thealose) 1 drop 4 times daily, starting $2 \mathrm{~h}$ after the operation, for 3 months; paracetamol $500 \mathrm{mg} 1$ tablet every $6 \mathrm{~h}$ for $24 \mathrm{~h}$ in case of pain; borage oil (Alphalarm) 1 capsule daily, starting the morning after surgery, for 3 months.

\section{Follow-Up and Outcomes}

The follow-up consisted of patient-perceived outcomes as well as photographic and ophthalmological assessments. The surgical procedure took place without any complications, and 1 day post-operatively, the patient reported: "Honestly, everything went well, knowing that it is the second day, I have no pain anymore. I find it looks natural enough, I have had some good comments, I am not disappointed." Eight months after the procedure, the patient reported to have experienced no problems and being satisfied with the result. The aesthetic aspect before and 8 months after the procedure is depicted in Figure 2.

The principal ophthalmological safety parameters are given in Table 1. It is clear from Table 1 that these parameters were stable during the follow-up period. In addition, optical coherence tomography pachymetry after 8 months (January 25, 2017) is depicted in Figure 3 . This figure confirms the stable presence of the pigment at $225 \mu \mathrm{m}$ depth. There is no sign of leakage or diffusion of the pigment in the cornea.

The visual field was normal $\left(60^{\circ}\right.$ temporally on both sides). The pre-operative topography compared to 8-month follow-up topography (differential topography) confirmed that there were no anatomical changes in both corneas (online suppl. material). There were no reported side effects at any time during follow-up.

\section{Discussion}

To our knowledge, this is the first comprehensive case report describing the safety and effectiveness of an annular keratopigmentation surgical procedure in a healthy subject, in line with the CARE clinical case reporting guidelines. The short- and medium-term safety of the procedure as employed in this subject is encouraging: there were no signs of leakage, diffusion, inflammation or any other detrimental effects on the cornea both objectively and subjectively. The pigment utilised appears to be stable. The vision of the patient was not affected negatively in any way, and the aesthetic results were good, as underlined by the high satisfaction of the patient.

Arguably, the most sensitive parameter of corneal health is the corneal endothelial cell count. It was encouraging to see that this cell count remained stable overall. A limitation of 


\section{Case Reports in Ophthalmology}

this case report is that 8 months of follow-up are insufficient for the assessment of long-term safety. Further medium- as well as long-term safety data are required.

We carefully developed our novel surgical technique (referred to as Neoris ${ }^{\circledR}$ ) and piloted its feasibility in an animal study [12]. Also, a special spatula that can be used for the preparation of the corneal tunnel and the insertion of the pigment was designed and developed [11]. The author (F.F.) was the first to use this technique for aesthetic purposes in humans in December 2013. This concerned a cancer patient who had a long held desire to change eye colour [13]. Contact with this patient was maintained, and in August 2017, she reported her continued satisfaction with the results as well as an absence of any procedurerelated side effects. The latter is encouraging from a long-term safety perspective.

An important aspect of the procedure is the pigment that is used. These pigments need to be highly stable and safe but also need to look "natural" from an aesthetic perspective. Further development and improvements in this regard are still possible and required.

The use of corneal tattooing procedures for aesthetic purposes is relatively novel in the field of ophthalmology. To our knowledge, 1 other centre developed a similar procedure in response to the need for treating iris and cornea defects $[3,4,9]$. They published a case series on aesthetic corneal tattooing using 3 different techniques, including femtosecondassisted keratopigmentation [14]. In general, the safety of the procedure was confirmed. However, in some of their patients, a second procedure for correction of the colour was required, and all patients reported mild to moderate photophobia, ranging from 2 weeks to 3 months post-operatively. In our patient, no colour correction was necessary, nor was photophobia reported post-operatively, and the aesthetic aspect seems to be more natural. The different pigment we are using could explain this.

To date (October 2017), we have treated 63 cases with this procedure, with positive results in terms of safety and effectiveness. As a next step, we plan to publish a case series, showing results in a wide variety of subjects.

For this procedure to be acceptable for purely aesthetic purposes, an excellent safety profile is an important requirement. This case and our further experiences obtained to date are highly encouraging in this regard. Our procedure is a promising safe and effective emerging possibility for those who want femtosecond-assisted annular keratopigmentation for purely aesthetic reasons, as well as for patients with ophthalmological pathologies affecting the appearance of the eyes.

\section{Acknowledgements}

We thank Dr Mark Bischoff and the late Dr Jean-Paul Tiziano for their help with the development of this surgical technique since its inception.

\section{Statement of Ethics}

This case is reported in accordance with the CARE Clinical Case Reporting guideline. The subject provided written informed consent for publication. 
Case Reports in
Ophthalmology

Case Rep Ophthalmol 2018;9:35-42

DOI: $10.1159 / 000485554$ (C) 2018 The Author(s)
www.karger.com/cop

Ferrari and van Haselen: The Safety and Effectiveness of a Novel Annular Keratopigmentation Method: A Case Report

\section{Disclosure Statement}

Francis Ferrari is the co-owner of Neoris ${ }^{\circledR}$, which is a distributor of the dye used.

\section{References}

1 Ziegler SL: Multicolor tattooing of the cornea. Trans Am Ophthalmol Soc 1922;20:71-87.

2 Hirsbein D, et al: Corneal tattooing for iris defects (in French). J Fr Ophtalmol 2008;31:155-164.

3 Alio JL, Rodriguez AE, Toffaha BT: Keratopigmentation (corneal tattooing) for the management of visual disabilities of the eye related to iris defects. Br J Ophthalmol 2011;95:1397-1401.

4 Alió JL, et al: Femtosecond-assisted keratopigmentation for functional and cosmetic restoration in essential iris atrophy. J Cataract Refract Surg 2011;37:1744-1747.

5 Roy JN: Tattooing of the cornea. Can Med Assoc J 1938;39:436-438.

6 Pitz S, et al: Corneal tattooing: an alternative treatment for disfiguring corneal scars. Br J Ophthalmol 2002;86:397-399.

7 Kymionis GD, et al: Femtosecond-assisted anterior lamellar corneal staining-tattooing in a blind eye with leukocoria. Cornea 2009;28:211-213.

8 Laria C, Alió JL, Piñero DP: Intrastromal corneal tattooing as treatment in a case of intractable strabismic diplopia (double binocular vision). Binocul Vis Strabismus Q 2010;25:238-242.

9 Alio JL, et al: Femtosecond-assisted keratopigmentation double tunnel technique in the management of a case of Urrets-Zavalia syndrome. Cornea 2012;31:1071-1074.

10 Gagnier JJ, et al: The CARE guidelines: consensus-based clinical case report guideline development. J Clin Epidemiol 2014;67:46-51.

11 Ferrari F: Instrument à main chirurgical (surgical hand instrument). I.N.P.I. (Institut National de la Propriété Industrielle), France, 2017.

12 Ferrari F, et al: La kératopigmentation annulaire (ou PresbyRing ${ }^{\circledR}$ ) dans la prise en charge de la presbytie: étude expérimentale de faisabilité post-mortem chez l'animal. J Fr Ophtalmol 2013;36:481487.

13 Ferrari F, Morin L: Description of a new method of changing eye color: case report of aesthetic annular keratopigmentation (AAK). J Fr Ophtalmol 2015;38:e3.

14 Alió JL, et al: Keratopigmentation to change the apparent color of the human eye: a novel indication for corneal tattooing. Cornea 2016;35:431-437. 
Case Reports in
Ophthalmology

Case Rep Ophthalmol 2018;9:35-42

DOI: $10.1159 / 000485554$

(c) 2018 www.karger.com/cop

Ferrari and van Haselen: The Safety and Effectiveness of a Novel Annular Keratopigmentation Method: A Case Report

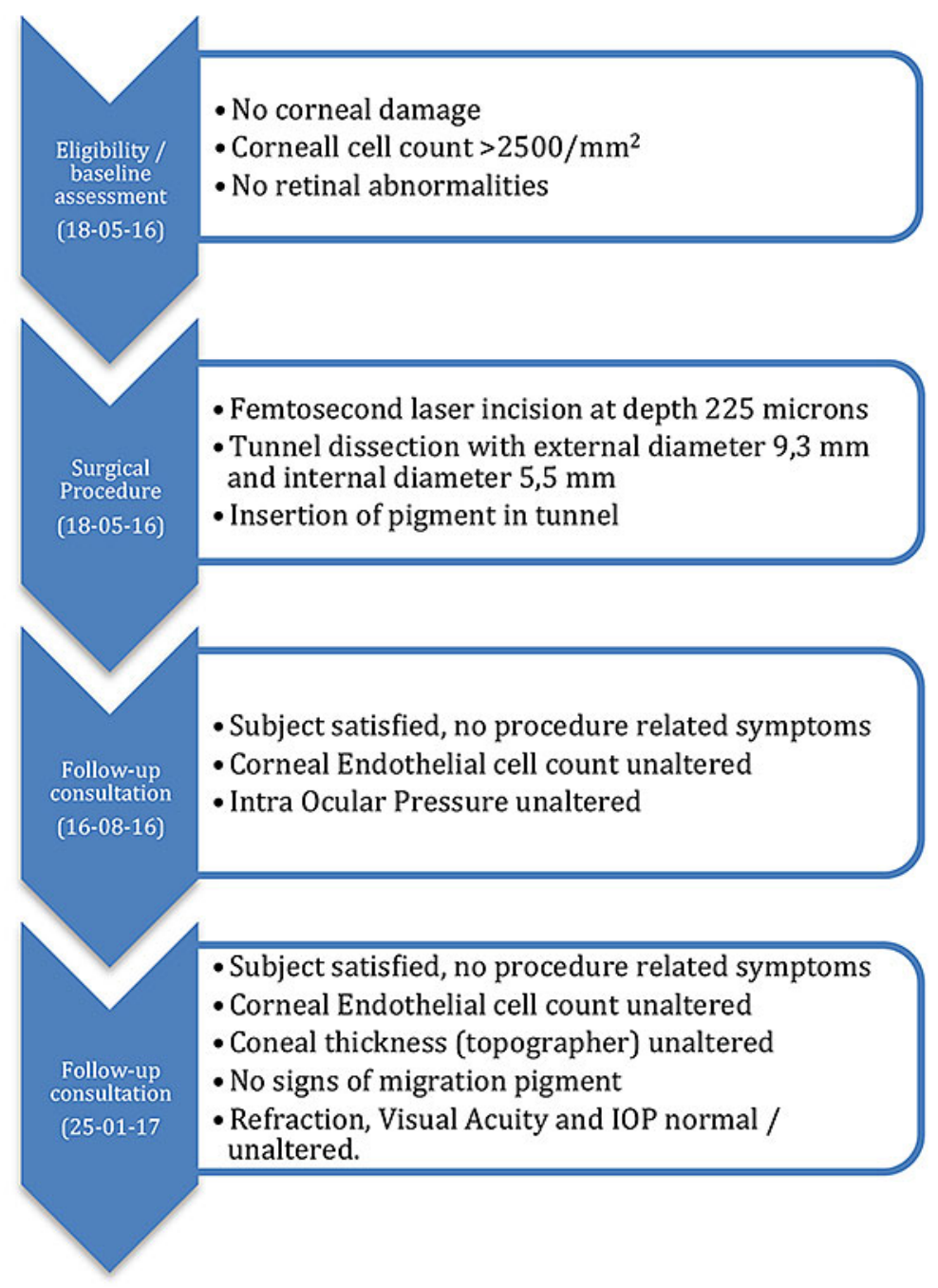

Fig. 1. Chronological summary. IOP, intra-ocular pressure. 
Case Reports in
Ophthalmology

Case Rep Ophthalmol 2018;9:35-42

\begin{tabular}{l|l}
\hline DOI: $10.1159 / 000485554$ & $\odot 2018$ The Author(s). Published by S. Karger AG, Basel \\
\hline
\end{tabular} www.karger.com/cop

Ferrari and van Haselen: The Safety and Effectiveness of a Novel Annular Keratopigmentation Method: A Case Report

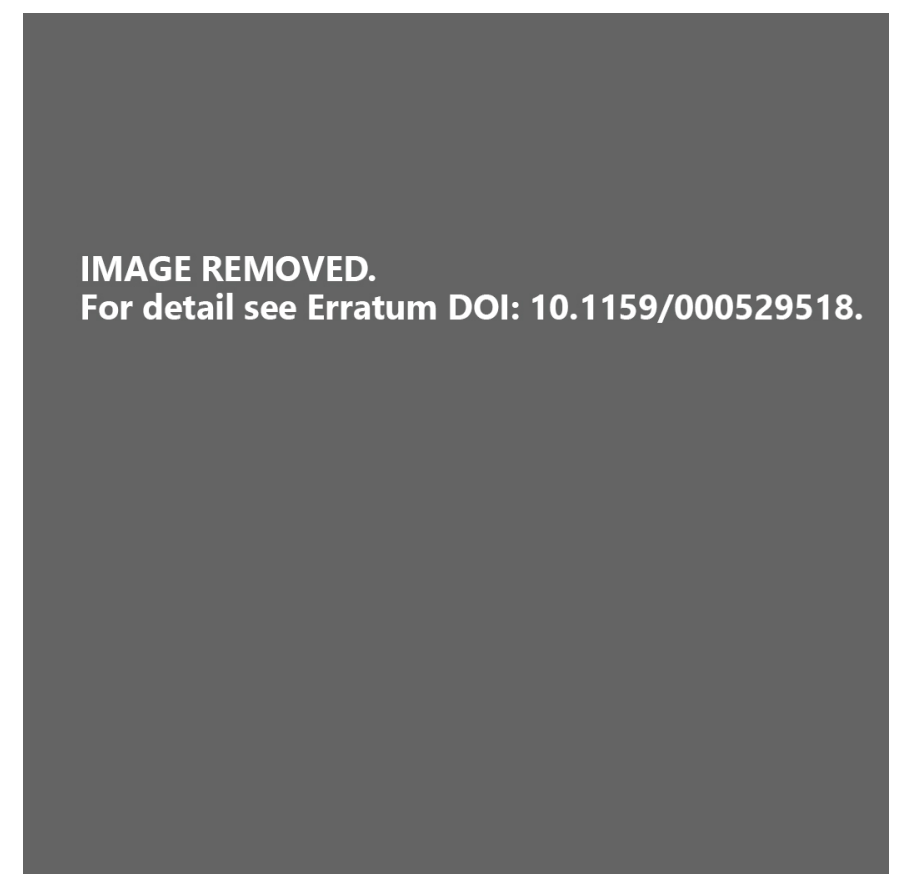

Fig. 2. Esthetic aspect before (top) and 8 months after (bottom) the procedure.

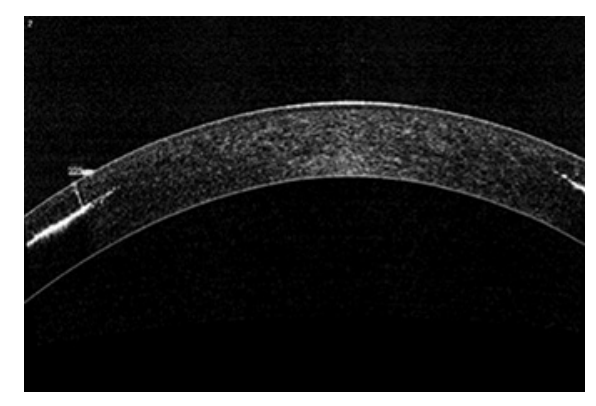

Fig. 3. Optical coherence tomography pachymetry 8 months after the procedure. 
Case Reports in
Ophthalmology

\begin{tabular}{l|l}
\hline Case Rep Ophthalmol 2018;9:35-42 \\
\hline DOI: 10.1159/000485554 & $\begin{array}{l}\text { @ 2018 The Author(s). Published by S. Karger AG, Basel } \\
\text { www.karger.com/cop }\end{array}$ \\
\hline
\end{tabular}

Ferrari and van Haselen: The Safety and Effectiveness of a Novel Annular Keratopigmentation Method: A Case Report

Table 1. Optical coherence tomography pachymetry 8 months after the procedure

\begin{tabular}{lllll}
\hline Date & $\begin{array}{l}\text { Corneal endothelial } \\
\text { cell count }\end{array}$ & Refraction and visual acuity & Pachymetry & $\begin{array}{l}\text { Intra-ocular } \\
\text { pressure }\end{array}$ \\
\hline May 18, 2016 & RE: 3,065 cells $/ \mathrm{mm}^{2}$ & RE: $+0.25\left(-0.25 / 175^{\circ}\right): 0.0 \operatorname{logMAR}$ & RE: $551 \mu \mathrm{m}$ & RE: $16 \mathrm{~mm} \mathrm{Hg}$ \\
& LE: 3,131 cells $/ \mathrm{mm}^{2}$ & LE: $+2.50\left(-0.50 / 110^{\circ}\right): 0.1 \operatorname{logMAR}$ & LE: $550 \mu \mathrm{m}$ & LE: $18 \mathrm{~mm} \mathrm{Hg}$ \\
\hline August 16, 2016 & RE: 3,012 cells $/ \mathrm{mm}^{2}$ & & & RE: $14 \mathrm{~mm} \mathrm{Hg}$ \\
& LE: 3,171 cells $/ \mathrm{mm}^{2}$ & & LE: $14 \mathrm{~mm} \mathrm{Hg}$ \\
\hline January 25, 2017 & RE: 3,104 cells $/ \mathrm{mm}^{2}$ & RE: $+0.25\left(-0.50 / 170^{\circ}\right): 0.0 \operatorname{logMAR}$ & RE: $543 \mu \mathrm{m}$ & RE: $16 \mathrm{~mm} \mathrm{Hg}$ \\
& LE: 3,036 cells $/ \mathrm{mm}^{2}$ & LE: $+2.50\left(-0.25 / 130^{\circ}\right): 0.1 \operatorname{logMAR}$ & LE: $545 \mu \mathrm{m}$ & LE: $16 \mathrm{~mm} \mathrm{Hg}$ \\
\hline
\end{tabular}

RE, right eye; LE, left eye. 